\title{
PK11195 enhances chemosensitivity to cisplatin and paclitaxel in human endometrial and ovarian cancer cells
}

\author{
NORIYUKI TAKAI, TAMI UEDA, MASAKAZU NISHIDA, KAEI NASU and HISASHI NARAHARA \\ Department of Obstetrics and Gynecology, Oita University Faculty of Medicine, Oita, Japan
}

Received August 3, 2009; Accepted September 21, 2009

DOI: 10.3892/ijmm_00000318

\begin{abstract}
The potential anticancer agent 1-(2-chlorophenyl$\mathrm{N}$-methylpropyl)-3-isoquinolinecarboxamide (PK11195), a translocator protein ligand, facilitates the induction of cell death by a variety of cytotoxic and chemotherapeutic agents in various human tumor cell lines. The purpose of this study was to elucidate the effect of PK11195 on three endometrial cancer cell lines, two ovarian cancer cell lines and normal human endometrial epithelial cells. Endometrial and ovarian cancer cells were treated with various concentrations of PK11195 alone or in combination with chemotherapeutic drugs (cisplatin, paclitaxel), and its effect on cell growth, the cell cycle, apoptosis and related measurements was investigated. The 3-(4,5-dimethylthiazol-2-yl)-2,5-diphenyltetrazolium bromide assay revealed that all endometrial and ovarian cancer cell lines were sensitive to the growthinhibitory effect of PK11195, although normal endometrial epithelial cells were viable after treatment with the same doses of PK11195 that induced growth inhibition in endometrial and ovarian cancer cells. Synergistic anti-neoplastic effects were obtained by a combination of PK11195 with cytostatic drugs. Induction of apoptosis was confirmed by annexin $\mathrm{V}$ staining of externalized phosphatidylserine and loss of the transmembrane potential of mitochondria. This induction occurred in concert with altered expression of genes related to apoptosis. These results suggest that PK11195 alone or in combination with chemotherapeutic drugs might be a new therapeutic option for the treatment of endometrial and ovarian cancers.
\end{abstract}

\section{Introduction}

Endometrial and ovarian cancers are the most common malignant tumors of the female genital tract. Although their incidences have increased in recent years (1), the search for

Correspondence to: Dr Noriyuki Takai, Department of Obstetrics and Gynecology, Oita University Faculty of Medicine, 1-1 Idaigaoka, Hasama-machi, Yufu-shi, Oita 879-5593, Japan

E-mail: takai@med.oita-u.ac.jp

Key words: translocator protein ligand, apoptosis, endometrial cancer, ovarian cancer agents effective in the treatment of either advanced or recurrent endometrial and ovarian cancers has been disappointing $(2,3)$. To date, cisplatin, doxorubicin and paclitaxel have demonstrated the greatest efficacy $(2,3)$. However, the duration of response remains between 4 to 8 months $(2,3)$. Therefore, innovative approaches are needed for the treatment of gynecological cancer.

The potential anticancer agent 1-(2-chlorophenyl-Nmethylpropyl)-3-isoquinolinecarboxamide (PK11195) facilitates the induction of cell death by a variety of agents including Fas ligand and chemotherapeutic drugs (4). Furthermore, in certain cell types, PK11195 alone is able to induce apoptosis $(5,6)$. PK11195 was initially described as a ligand for the peripheral benzodiazepine receptor (7), whose new proposed name is translocator protein (18 kDa) (TSPO) (8). TSPO is a transmembrane protein that is located mainly in the outer mitochondrial membrane, but is also expressed in other subcellular compartments. TSPO is associated with the regulation of cholesterol transport, the synthesis of steroid hormones, porphyrin transport, heme synthesis, apoptosis and cell proliferation (8). Other chemically unrelated TSPO ligands induce apoptosis in different cell types $(5,6)$, indicating a TSPO-dependent mechanism; however, TSPO-independent mechanisms have been proposed to inhibit cell proliferation or sensitize cells to apoptosis (9). It has been reported that PK11195 induces apoptosis by altering the mitochondrial permeability transition pore complex (PTPC) (4). In recent years, it has been widely accepted that apoptosis is under the control of mitochondria and that PTPC plays a key role in this regulation (10). PTPC is intimately involved in the initiation and regulation of apoptosis by controlling mitochondrial membrane potential and releasing proapoptotic factors from the mitochondria $(11,12)$. Opening of the PTPC induces apoptosis, whereas pharmacological inhibition of this pore prevents cell death. Concurrently, the oncoprotein Bcl-2, which is particularly abundant at the location of the PTPC (13), prevents apoptosis induction (14). Notably, in a variety of systems, PK11195 can reduce or abrogate the antiapoptotic effect of Bcl-2-like proteins, including Bcl-2 and Bcl-xL (15) by facilitating pore opening, induced by cytotoxic stimuli leading to cessation of oxidative phosphorylation and activation of the cascade that mediates the features of apoptosis (16).

Importantly, PK11195 concentrations that were effective in these preclinical studies have been safely achieved in patients $(17,18)$. However, the effect of PK11195 on endometrial and ovarian cancer cells has not yet been well 
described. This motivated us to examine the effect of PK11195 on endometrial and ovarian cancer cell lines for the first time. Since endometrial and ovarian cancer cells overexpress TSPO $(19,20)$ and Bcl-2 $(21,22)$, we decided to examine the effects of PK11195 on endometrial and ovarian cancer cells.

\section{Materials and methods}

Cell lines. The Ishikawa human endometrial cancer cell line was kindly provided by Dr Masato Nishida (Tsukuba University, Ibaraki, Japan). The HHUA human endometrial cancer cell line was obtained from Riken (Ibaraki, Japan). The HEC-1B human endometrial cancer cell line and the SK-OV-3 human ovarian cancer cell line were obtained from American Type Culture Collection (Manassas, VA, USA). The OMC-3 human ovarian cancer cell line was kindly provided by Dr Masatsugu Ueda (Osaka Medical College, Osaka, Japan). The Ishikawa cells were maintained as monolayers at $37^{\circ} \mathrm{C}$ in $5 \% \mathrm{CO}_{2} /$ air in Dulbecco's modified Eagle's medium (DMEM; Gibco, Rockville, MD, USA) containing 5\% heatinactivated fetal bovine serum (FBS; Omega, Tarzana, CA, USA). The other four cell lines were maintained as monolayers at $37^{\circ} \mathrm{C}$ in $5 \% \mathrm{CO}_{2}$ /air in Roswell Park Memorial Institute (RPMI)-1640 medium (Gibco) containing $10 \%$ heatinactivated FBS (Omega).

Normal endometrial epithelial cells. Normal endometrial specimens were obtained from ten pre-menopausal patients who had undergone hysterectomies for leiomyoma. All patients had been free of any hormonal treatments before the operation. All of the specimens were determined as being from the late proliferative phase (11th-13th day of the menstrual cycle) using a standard histological examination of endometrial tissues. This study was approved by the Institutional Review Board (IRB) of the Faculty of Medicine, Oita University, and written informed consent was obtained from all patients.

Normal endometrial epithelial cells were separated from stromal cells by digesting the tissue fragments with collagenase, as described (23).

Chemicals. PK11195 was obtained from Biomol (Plymouth Meeting, PA, USA). Diazepam, cisplatin, and paclitaxel were purchased from Sigma (St. Louis, MO, USA).

MTT assays. 3-(4,5-Dimethylthiazol-2-yl)-2,5-diphenyltetrazolium bromide (MTT; Sigma) was dissolved in phosphate-buffered saline (PBS; $5 \mathrm{mg} / \mathrm{ml}$ ) and was used to measure cellular proliferation. Cells $\left(1 \times 10^{3}\right)$ were incubated with $100 \mu \mathrm{l}$ of culture medium for $72 \mathrm{~h}$ in 96 -well plates, and $10 \mu \mathrm{l}$ of MTT solution was added. After $4 \mathrm{~h}$ of incubation, solubilization solution ( $50 \mu 1$ of $20 \%$ SDS) was added, and cells were then incubated at $37^{\circ} \mathrm{C}$ for $16 \mathrm{~h}$. In this assay, MTT is cleaved to an orange formazan dye by metabolically active cells. The dye was directly quantified using an enzymelinked immunosorbent assay reader at $540 \mathrm{~nm}$.

Cell cycle analysis by flow cytometry. The cell cycle was analyzed by flow cytometry after 3 days of culturing, as described (23). Cells $\left(5 \times 10^{4}\right)$ were exposed to PK11195, cisplatin or paclitaxel in 6-well, flat-bottomed plates for $72 \mathrm{~h}$. Analysis was performed immediately after staining using the CELLFit program (Becton Dickinson, San Jose, CA, USA), whereby the S-phase was calculated using an RFit model.

Measurement of apoptosis (flow cytometric analysis with the annexin V/propidium iodide assay). Cells were plated and grown overnight until they reached $80 \%$ confluence, and then treated with PK11195, cisplatin or paclitaxel. After 72 h, detached cells in the medium were collected, and the remaining adherent cells were harvested by trypsinization. The cells $\left(1 \times 10^{5}\right)$ were washed with PBS and resuspended in $250 \mu 1$ of binding buffer (AnnexinV-FITC Kit; Becton Dickinson) containing $10 \mu \mathrm{l}$ of $20 \mu \mathrm{g} / \mathrm{ml} \mathrm{PI}$ and $5 \mu \mathrm{l}$ of annexin V-FITC, which binds to phosphatidylserine translocated to the exterior of the cell membrane early in the apoptosis pathway as well as during necrosis. After incubation for $10 \mathrm{~min}$ at room temperature in a light-protected area, the samples were analyzed on a FACSCalibur flow cytometer (Becton Dickinson). FITC and PI emissions were detected in the FL-1 and FL-2 channels, respectively. For each sample, data from 30,000 cells were recorded in list mode on logarithmic scales. Subsequent analysis was conducted with CellQuest software (Becton Dickinson).

Mitochondrial transmembrane potential. Cells were prepared for FACS as described above and stained using the Mitocapture Apoptosis Detection Kit obtained from Biovision (Palo Alto, CA, USA) with a fluorescent lipophilic cationic reagent that assesses mitochondrial membrane permeability according to the manufacturer's recommendation as described (23).

Western blot analysis. Cells were washed twice in PBS, suspended in lysis buffer [50 mM Tris ( $\mathrm{pH} 8.0), 150 \mathrm{mM}$ $\mathrm{NaCl}, 0.1 \%$ SDS, $0.5 \%$ sodium deoxycholate, $1 \%$ NP40, phenylmethylsulfonyl fluoride at $100 \mu \mathrm{g} / \mathrm{ml}$, aprotinin at $2 \mu \mathrm{g} /$ $\mathrm{ml}$, pepstatin at $1 \mu \mathrm{g} / \mathrm{ml}$ and leupeptin at $10 \mu \mathrm{g} / \mathrm{ml}]$ and placed on ice for $30 \mathrm{~min}$. After centrifugation at $15,000 \mathrm{x} \mathrm{g}$ for $15 \mathrm{~min}$ at $4^{\circ} \mathrm{C}$, the suspension was collected. Protein concentrations were quantified using the Bio-Rad protein Assay Dye Reagent Concentrate (Bio-Rad Laboratories, Hercules, CA, USA) according to the manufacturer's recommendation. Whole cell lysates $(40 \mu \mathrm{g})$ were resolved by SDS-PAGE in a $4-15 \%$ gel, transferred to a polyvinylidene difluoride membrane (Immobilon; Amersham, Arlington Heights, IL, USA), and probed sequentially with antibodies against bcl-2 (1:1,000, BD Pharmingen, San Jose, CA, USA), bcl-xL (1:1,000, BD Pharmingen), bax $(1: 1,000$, BD Pharmingen), cleaved caspase-3 (1:1,000, BD Pharmingen), cleaved caspase-8 (1:1,000, Calbiochem, San Diego, CA, USA), cleaved caspase-9 (1:1,000, Calbiochem), and GAPDH mAb (1:10,000, Research Diagnostics, Flanders, NJ, USA). The blots were developed using the Enhanced Chemiluminescent (ECL) Kit (Amersham).

Statistical analysis. All experiments were conducted independently at least three times in triplicate per experimental point. All numerical data were expressed as means \pm SD. 

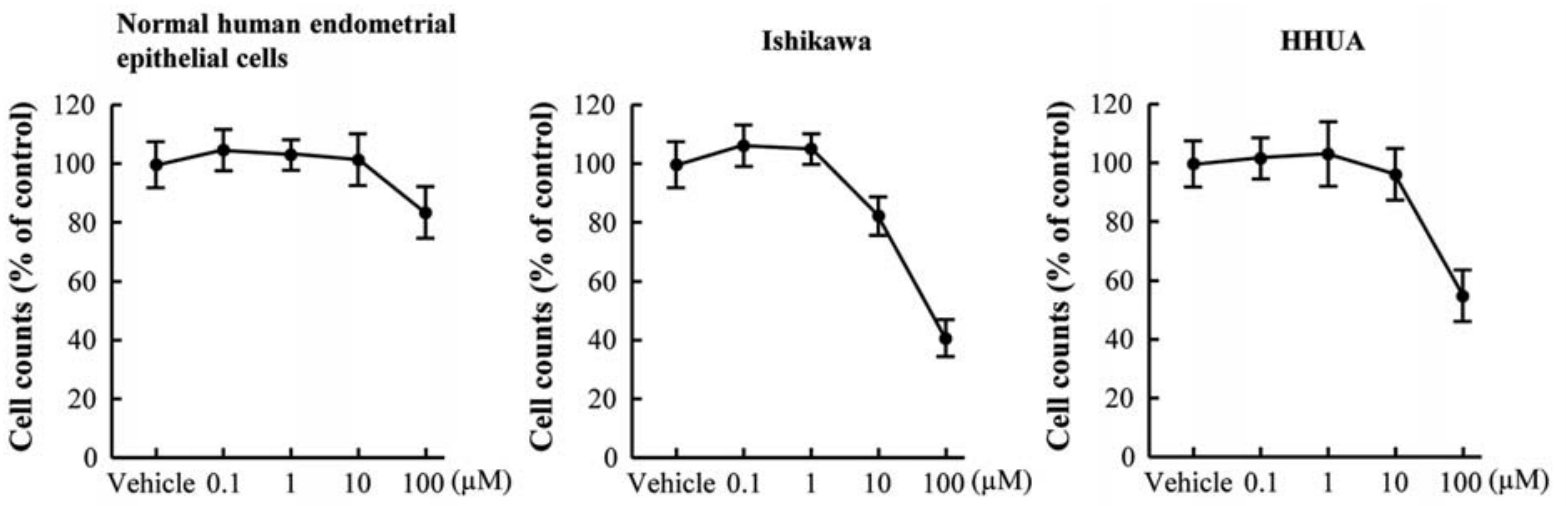

HEC-1B

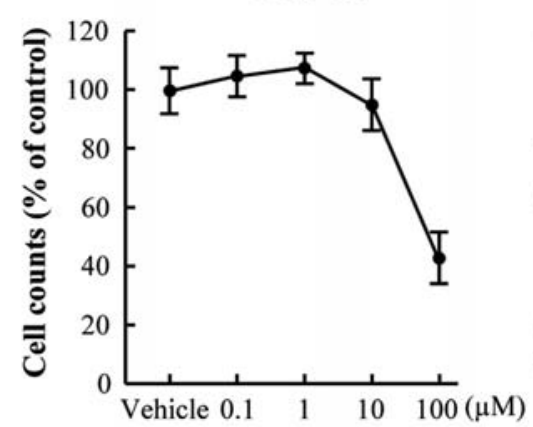

SK-OV-3

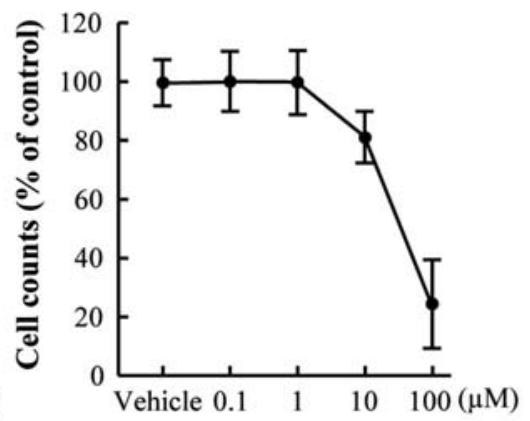

OMC-3

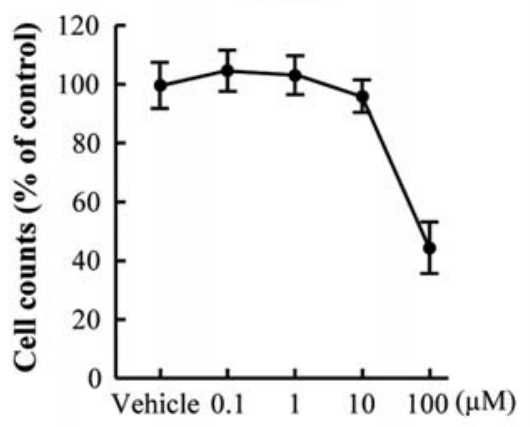

Figure 1. Effect of the TSPO ligand PK11195 on the growth of endometrial and ovarian cancer cell lines, and normal human endometrial epithelial cells (NHEEC) in vitro. Ishikawa, HHUA and HEC-1B endometrial cancer cells; SK-OV-3 and OMC-3 ovarian cancer cells; and normal human endometrial epithelial cells were treated with either PK11195 at various concentrations ( $\left.1 \times 10^{-7}-1 \times 10^{-4} \mathrm{M}\right)$ or the dilutant (control) for $72 \mathrm{~h}$, and the growth (\% of control) was measured using an MTT assay. Results represent the means \pm SD of three independent experiments with triplicate dishes.

Significance was determined by conducting a paired Student's t-test.

\section{Results}

Effects of PK11195 on the proliferation and viability of normal human endometrial epithelial cells, endometrial cancer cell lines, and ovarian cancer cell lines in vitro. We examined the antitumor effects of PK11195 on normal human endometrial epithelial cells (NHEEC), three endometrial cancer cell lines, and two ovarian cancer cell lines in vitro, using an MTT assay with a 3-day exposure to PK11195 (Fig. 1). Ishikawa endometrial cancer cells, HHUA endometrial cancer cells, HEC-1B endometrial cancer cells, SKOV-3 ovarian cancer cells and OMC-3 ovarian cancer cells showed significant sensitivity to PK11195 at 10-100 $\mu \mathrm{M}$, which caused a $50 \%$ inhibition $\left(\mathrm{ED}_{50}\right)$ in their growth. On the other hand, NHEEC showed little sensitivity to PK11195 at $100 \mu \mathrm{M}$.

The non-selective TSPO compound diazepam did not show any inhibitory effect on cell survival (Table I).

TSPO ligand PK11195 chemosensitizes endometrial and ovarian cancer cells to treatment with cisplatin or paclitaxel. We next investigated whether the combination of TSPO ligand with cytostatic drugs was superior to the antiproliferative treatment with single agents. For combination
Table I. Cell survival.

\begin{tabular}{lcc}
\hline & PK11195 $(100 \mu \mathrm{M})$ & Diazepam $(100 \mu \mathrm{M})$ \\
\hline NHEEC & $80 \pm 15$ & $92 \pm 5$ \\
Ishikawa & $40 \pm 8$ & $89 \pm 10$ \\
HHUA & $52 \pm 13$ & $94 \pm 3$ \\
HEC-1B & $42 \pm 9$ & $90 \pm 7$ \\
SK-OV-3 & $23 \pm 16$ & $85 \pm 15$ \\
OMC-3 & $43 \pm 11$ & $93 \pm 5$ \\
\hline
\end{tabular}

Cell survival is expressed as the percentage of the control. NHEEC, normal human endometrial epithelial cells. Each experiment was repeated three times. Means \pm SD.

treatments, individual drugs were used at two different concentrations between their respective $\mathrm{IC}_{10}$ and $\mathrm{IC}_{50}$ values. The combination of either cytostatic drug with PK11195 acted in a synergistic way (Ishikawa cells, Fig. 2; other cell lines, data not shown).

Cell cycle analysis of endometrial and ovarian cancer cells after exposure to PK11195 in combination with chemotherapeutic drugs. Based on the synergism between the TSPO ligand and cisplatin or paclitaxel, we next investigated 
Table II. Cell cycle changes in endometrial and ovarian cancer cell lines.

\begin{tabular}{|c|c|c|c|c|c|c|c|}
\hline & & Vehicle & $\begin{array}{c}\text { PK11195 } \\
(10 \mu \mathrm{M})\end{array}$ & $\begin{array}{l}\text { Cisplatin } \\
(100 \mathrm{nM})\end{array}$ & $\begin{array}{l}\text { Paclitaxel } \\
\quad(5 \mathrm{nM})\end{array}$ & $\begin{array}{l}\text { PK11195 }(10 \mu \mathrm{M}) \\
\text { Cisplatin }(100 \mathrm{nM})\end{array}$ & $\begin{array}{c}\text { PK11195 }(10 \mu \mathrm{M}) \\
\text { Paclitaxel }(5 \mathrm{nM})\end{array}$ \\
\hline \multirow[t]{4}{*}{ Ishikawa } & Sub G0/G1 (\%) & $2 \pm 0$ & $15 \pm 8$ & $20 \pm 9$ & $22 \pm 7$ & $58 \pm 28$ & $60 \pm 23$ \\
\hline & G0/G1 (\%) & $52 \pm 7$ & $55 \pm 16$ & $50 \pm 9$ & $58 \pm 10$ & $27 \pm 10$ & $22 \pm 13$ \\
\hline & $\mathrm{S}(\%)$ & $25 \pm 5$ & $14 \pm 3$ & $12 \pm 7$ & $9 \pm 3$ & $6 \pm 5$ & $8 \pm 7$ \\
\hline & $\mathrm{G} 2 / \mathrm{M}(\%)$ & $21 \pm 7$ & $16 \pm 8$ & $18 \pm 4$ & $11 \pm 8$ & $9 \pm 7$ & $10 \pm 8$ \\
\hline \multirow[t]{4}{*}{ HHUA } & Sub G0/G1 (\%) & $1 \pm 0$ & $5 \pm 4$ & $11 \pm 7$ & $13 \pm 6$ & $33 \pm 12$ & $38 \pm 16$ \\
\hline & G0/G1 (\%) & $40 \pm 6$ & $48 \pm 10$ & $51 \pm 6$ & $56 \pm 10$ & $28 \pm 11$ & $23 \pm 9$ \\
\hline & $\mathrm{S}(\%)$ & $39 \pm 6$ & $33 \pm 14$ & $19 \pm 6$ & $11 \pm 7$ & $12 \pm 8$ & $14 \pm 5$ \\
\hline & $\mathrm{G} 2 / \mathrm{M}(\%)$ & $20 \pm 3$ & $14 \pm 8$ & $19 \pm 9$ & $20 \pm 5$ & $27 \pm 12$ & $25 \pm 13$ \\
\hline \multirow[t]{4}{*}{ HEC-1B } & Sub G0/G1 (\%) & $1 \pm 0$ & $8 \pm 3$ & $12 \pm 9$ & $16 \pm 7$ & $38 \pm 11$ & $41 \pm 25$ \\
\hline & G0/G1 (\%) & $45 \pm 9$ & $51 \pm 13$ & $48 \pm 11$ & $50 \pm 16$ & $41 \pm 15$ & $38 \pm 18$ \\
\hline & $\mathrm{S}(\%)$ & $35 \pm 7$ & $24 \pm 7$ & $19 \pm 13$ & $21 \pm 15$ & $13 \pm 8$ & $17 \pm 15$ \\
\hline & $\mathrm{G} 2 / \mathrm{M}(\%)$ & $19 \pm 6$ & $17 \pm 8$ & $31 \pm 17$ & $13 \pm 7$ & $8 \pm 8$ & $4 \pm 3$ \\
\hline \multirow[t]{4}{*}{ SK-OV-3 } & Sub G0/G1 (\%) & $3 \pm 0$ & $17 \pm 5$ & $21 \pm 10$ & $18 \pm 9$ & $48 \pm 15$ & $46 \pm 12$ \\
\hline & G0/G1 (\%) & $50 \pm 6$ & $59 \pm 10$ & $35 \pm 16$ & $44 \pm 12$ & $39 \pm 10$ & $33 \pm 12$ \\
\hline & $\mathrm{S}(\%)$ & $39 \pm 7$ & $13 \pm 5$ & $29 \pm 11$ & $24 \pm 9$ & $5 \pm 3$ & $11 \pm 9$ \\
\hline & $\mathrm{G} 2 / \mathrm{M}(\%)$ & $8 \pm 3$ & $11 \pm 3$ & $15 \pm 7$ & $14 \pm 7$ & $8 \pm 3$ & $10 \pm 7$ \\
\hline \multirow[t]{4}{*}{ OMC-3 } & Sub G0/G1 (\%) & $4 \pm 1$ & $5 \pm 3$ & $11 \pm 5$ & $14 \pm 6$ & $35 \pm 13$ & $33 \pm 12$ \\
\hline & G0/G1 (\%) & $42 \pm 8$ & $55 \pm 17$ & $46 \pm 18$ & $60 \pm 21$ & $46 \pm 23$ & $45 \pm 10$ \\
\hline & $\mathrm{S}(\%)$ & $33 \pm 9$ & $31 \pm 16$ & $25 \pm 12$ & $16 \pm 11$ & $9 \pm 3$ & $11 \pm 6$ \\
\hline & $\mathrm{G} 2 / \mathrm{M}(\%)$ & $21 \pm 8$ & $9 \pm 7$ & $18 \pm 6$ & $10 \pm 3$ & $10 \pm 7$ & $11 \pm 3$ \\
\hline
\end{tabular}

Endometrial and ovarian cancer cells were plated in triplicate wells, grown for 3 days, and the cell cycle distribution was measured. Means \pm SD.

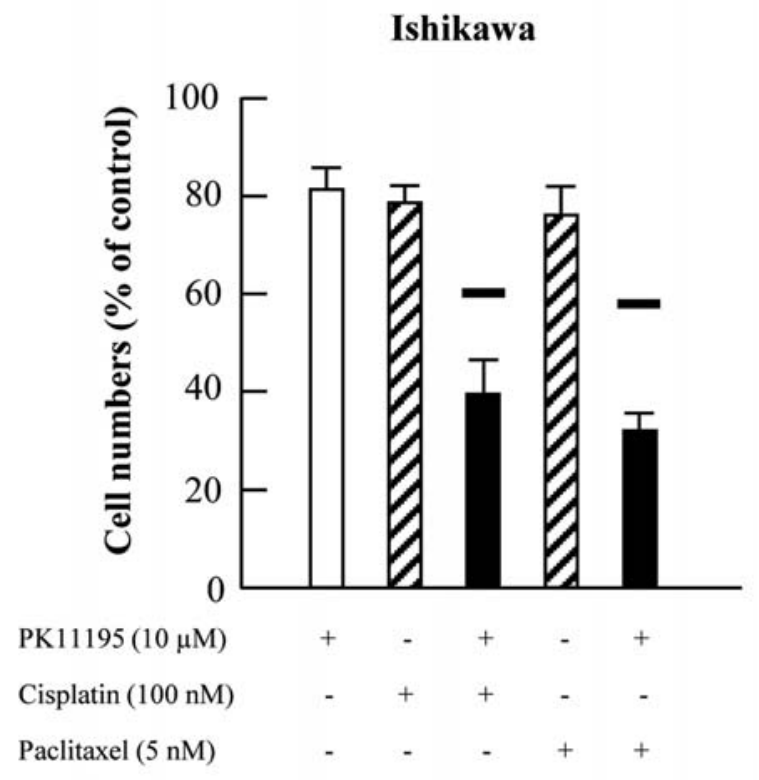

Figure 2. Synergistic growth inhibition of Ishikawa endometrial cancer cells by cytostatic drugs when combined with the TSPO ligand PK11195. Combination treatment with sub- $\mathrm{IC}_{50}$ concentrations of cytostatic agents (cisplatin, paclitaxel) and the TSPO-ligand PK11195 for $72 \mathrm{~h}$ led to synergistic growth inhibitory effects in Ishikawa cells. Black bars indicate the values of the calculated additive growth inhibition. Data are expressed as the percentage of untreated controls (means \pm SD of at least three independent experiments). whether this combination led to synergistic induction of apoptosis and/or cell cycle arrest in endometrial and ovarian cancer cells. The combination of the TSPO ligand and cisplatin or paclitaxel led to a dramatic increase in sub G0/ G1 apoptotic cells compared to treatment with either agent alone (Table II). This was representative of all cell lines tested.

Apoptotic changes in endometrial and ovarian cancer cells treated with PK11195 and cytostatic agents. To assess the capability of endometrial and ovarian cancer cells to undergo apoptosis in response to drug exposure and to help distinguish between different types of cell death, we double-stained PK11195 and cytostatic agent-treated cells with annexin V and PI and analyzed the results using flow cytometry. Annexin $\mathrm{V}$ binding combined with PI labeling was performed to discriminate early apoptotic (annexin $\mathrm{V}^{+/}$propidium iodide ${ }^{-}$) and necrotic (annexin $\mathrm{V}^{+} /$propidium iodide ${ }^{+}$) cells. The combination of the TSPO ligand and cisplatin or paclitaxel led to a simultaneous increase in both the annexin $\mathrm{V}^{+}$/ propidium iodide- fraction (early apoptotic) and annexin $\mathrm{V}^{+}$ propidium iodide ${ }^{+}$(regarded as necrotic) subpopulations (Table III). This was representative of all cell lines tested.

Loss of MTP in response to combination treatment with PK11195 and cytostatic agents. Loss of MTP has been shown to occur prior to nuclear condensation and caspase 
Table III. Cell death measured by annexin V and MTP assays detected by flow cytometry in endometrial and ovarian cancer cells.

$\begin{array}{cccccc}\text { Vehicle } & \text { PK11195 } & \text { Cisplatin } & \text { Paclitaxel } & \text { PK11195 }(10 \mu \mathrm{M}) & \text { PK11195 }(10 \mu \mathrm{M}) \\ & (10 \mu \mathrm{M}) & (100 \mathrm{nM}) & (5 \mathrm{nM}) & \text { Cisplatin }(100 \mathrm{nM}) & \text { Paclitaxel }(5 \mathrm{nM})\end{array}$

\begin{tabular}{|c|c|c|c|c|c|c|c|}
\hline \multicolumn{8}{|c|}{ Annexin V assay } \\
\hline \multirow[t]{3}{*}{ Ishikawa } & Viable (LL) (\%) & $95 \pm 4$ & $80 \pm 9$ & $78 \pm 11$ & $76 \pm 19$ & $38 \pm 11$ & $35 \pm 9$ \\
\hline & Apoptosis (LR) (\%) & $2 \pm 1$ & $11 \pm 5$ & $12 \pm 11$ & $9 \pm 6$ & $45 \pm 18$ & $33 \pm 25$ \\
\hline & Necrosis (UR) (\%) & $2 \pm 1$ & $6 \pm 5$ & $10 \pm 12$ & $13 \pm 8$ & $16 \pm 15$ & $29 \pm 15$ \\
\hline \multirow[t]{3}{*}{ HHUA } & Viable (LL) (\%) & $90 \pm 2$ & $88 \pm 9$ & $80 \pm 12$ & $78 \pm 11$ & $44 \pm 16$ & $42 \pm 12$ \\
\hline & Apoptosis (LR) $(\%)$ & $1 \pm 0$ & $7 \pm 8$ & $8 \pm 7$ & $11 \pm 10$ & $27 \pm 13$ & $30 \pm 8$ \\
\hline & Necrosis (UR) (\%) & $4 \pm 1$ & $4 \pm 3$ & $9 \pm 4$ & $10 \pm 3$ & $29 \pm 11$ & $25 \pm 17$ \\
\hline \multirow[t]{3}{*}{ HEC-1B } & Viable (LL) (\%) & $92 \pm 7$ & $90 \pm 20$ & $86 \pm 17$ & $82 \pm 23$ & $51 \pm 26$ & $48 \pm 16$ \\
\hline & Apoptosis (LR) (\%) & $2 \pm 1$ & $5 \pm 3$ & $5 \pm 4$ & $7 \pm 5$ & $27 \pm 11$ & $25 \pm 8$ \\
\hline & Necrosis (UR) (\%) & $4 \pm 2$ & $5 \pm 4$ & $9 \pm 6$ & $8 \pm 4$ & $19 \pm 3$ & $24 \pm 7$ \\
\hline \multirow[t]{3}{*}{ SK-OV-3 } & Viable (LL) (\%) & $89 \pm 5$ & $81 \pm 15$ & $78 \pm 24$ & $75 \pm 18$ & $48 \pm 16$ & $45 \pm 12$ \\
\hline & Apoptosis (LR) (\%) & $3 \pm 1$ & $9 \pm 5$ & $7 \pm 6$ & $9 \pm 8$ & $32 \pm 15$ & $36 \pm 12$ \\
\hline & Necrosis (UR) (\%) & $3 \pm 1$ & $10 \pm 7$ & $11 \pm 6$ & $13 \pm 7$ & $19 \pm 6$ & $17 \pm 13$ \\
\hline \multirow[t]{3}{*}{ OMC-3 } & Viable (LL) (\%) & $93 \pm 6$ & $86 \pm 11$ & $85 \pm 14$ & $83 \pm 14$ & $58 \pm 16$ & $41 \pm 19$ \\
\hline & Apoptosis (LR) (\%) & $4 \pm 2$ & $5 \pm 4$ & $8 \pm 7$ & $9 \pm 7$ & $26 \pm 17$ & $37 \pm 9$ \\
\hline & Necrosis (UR) (\%) & $2 \pm 1$ & $6 \pm 3$ & $5 \pm 3$ & $8 \pm 4$ & $13 \pm 7$ & $21 \pm 13$ \\
\hline \multicolumn{8}{|l|}{ MTP assay } \\
\hline \multirow[t]{2}{*}{ Ishikawa } & Viable $(\%)$ & $98 \pm 0$ & $84 \pm 10$ & $78 \pm 9$ & $78 \pm 7$ & $45 \pm 16$ & $40 \pm 20$ \\
\hline & Apoptosis (\%) & $2 \pm 0$ & $16 \pm 8$ & $22 \pm 7$ & $22 \pm 9$ & $55 \pm 20$ & $60 \pm 25$ \\
\hline \multirow[t]{2}{*}{ HHUA } & Viable $(\%)$ & $99 \pm 0$ & $95 \pm 4$ & $85 \pm 3$ & $87 \pm 9$ & $65 \pm 9$ & $66 \pm 14$ \\
\hline & Apoptosis (\%) & $1 \pm 0$ & $5 \pm 1$ & $15 \pm 2$ & $13 \pm 4$ & $35 \pm 10$ & $34 \pm 9$ \\
\hline \multirow[t]{2}{*}{ HEC-1B } & Viable $(\%)$ & $99 \pm 0$ & $89 \pm 7$ & $88 \pm 9$ & $82 \pm 8$ & $62 \pm 11$ & $61 \pm 20$ \\
\hline & Apoptosis (\%) & $1 \pm 0$ & $11 \pm 7$ & $12 \pm 7$ & $18 \pm 5$ & $38 \pm 10$ & $39 \pm 21$ \\
\hline \multirow[t]{2}{*}{ SK-OV-3 } & Viable $(\%)$ & $97 \pm 2$ & $83 \pm 6$ & $83 \pm 10$ & $82 \pm 8$ & $56 \pm 17$ & $58 \pm 15$ \\
\hline & Apoptosis (\%) & $3 \pm 1$ & $17 \pm 2$ & $17 \pm 5$ & $18 \pm 5$ & $44 \pm 11$ & $42 \pm 18$ \\
\hline \multirow[t]{2}{*}{ OMC-3 } & Viable $(\%)$ & $97 \pm 1$ & $91 \pm 4$ & $85 \pm 5$ & $91 \pm 5$ & $55 \pm 13$ & $60 \pm 19$ \\
\hline & Apoptosis (\%) & $3 \pm 1$ & $9 \pm 3$ & $15 \pm 5$ & $19 \pm 5$ & $45 \pm 18$ & $40 \pm 17$ \\
\hline
\end{tabular}

Each experiment was repeated three times. Means \pm SD.

activation and is linked to cytochrome $c$ release in many, but not all, apoptotic cells (24). Using MitoCapture staining and flow cytometry, we analyzed MTP in three endometrial and ovarian cancer cell lines treated with PK11195 alone or in combination with chemotherapeutic drugs (cisplatin or paclitaxel). Intracellular fluorescence was assayed by FACS after loading cells with an intramitochondrial dye. High fluorescence at $575 \mathrm{~nm}$ (FL2) corresponds to the aggregated form of the dye and is proportional to an intact MTP, whereas loss of MTP leads to a loss of 575 fluorescence and an increase in fluorescence at $525 \mathrm{~nm}$ (FL1; monomeric form of the dye). Treatment of cells with PK11195 and cytostatic agents resulted in loss of 575 fluorescence and an increase in fluorescence at 525, indicating loss of MTP (Table III).
Effect of combination treatment with PK11195 and cytostatic agents on the expression of apoptosis-related proteins. Antiapoptotic members of the Bcl-2 protein family localize to the outer mitochondrial membrane and regulate the mitochondrial release of apoptogenic proteins. The combination treatment with PK11195 and cytostatic agents was found to reverse $\mathrm{Bcl}-2$ and $\mathrm{Bcl}-\mathrm{xL}$ action with no change in Bax expression (Fig. 3). The Bcl-2 family of apoptosis-regulating proteins function either to promote (Bax, Bad, Bak) or inhibit (Bcl-2, Bcl-xL, and Mcl-1) the apoptotic response to a wide variety of stimuli, including chemotherapy and radiotherapy (reviewed in ref. 25).

Within the mitochondrial membrane, TSPO is known to contribute to the formation of the permeability transition pore. 

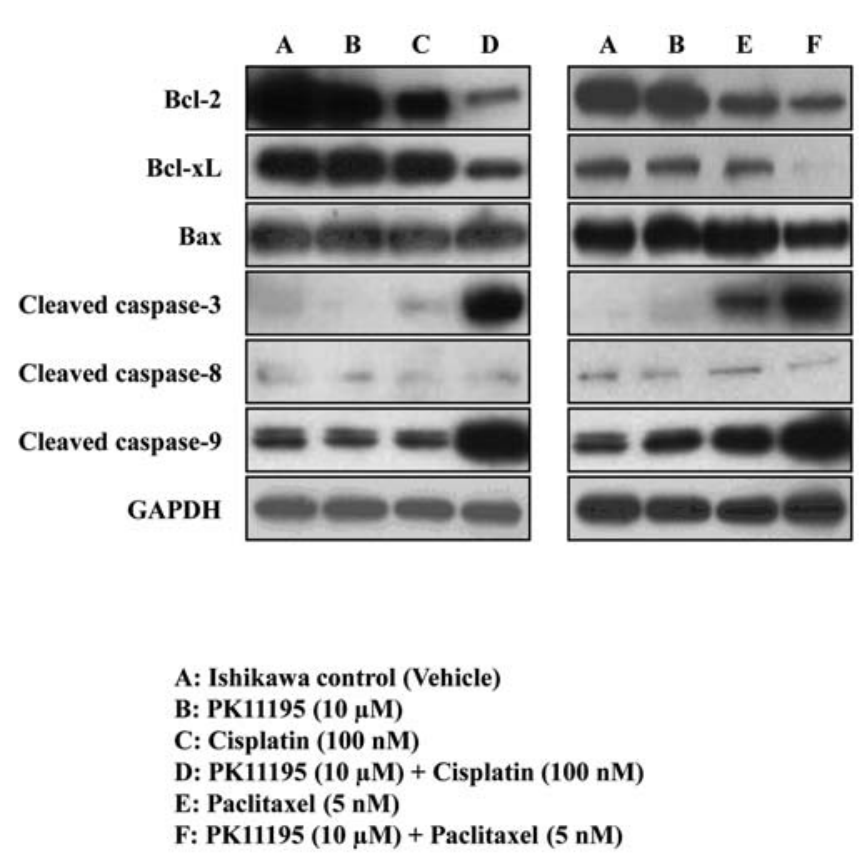

Figure 3. Apoptosis-related protein expression in Ishikawa cells measured by Western blot analysis. Ishikawa cells were treated with sub- $\mathrm{IC}_{50}$ concentrations of cytostatic agents (cisplatin, paclitaxel) and the TSPO-ligand PK11195, and cell lysates were harvested after $72 \mathrm{~h}$. Western blot analysis was performed with a series of antibodies while the control cells were treated with vehicle alone. The amount of protein was normalized by comparison to GAPDH levels.

This pore is considered to play a central role in the initiation of apoptosis (26). Our results demonstrate that caspase- 3 and -9 activation are involved in PK11195 and chemotherapeutic drug-induced apoptosis of human endometrial and ovarian cancer cells. However, the combination of PK11195 and cytostatic agents had no influence on caspase- 8 activation (Fig. 3).

\section{Discussion}

Our results showed that the specific TSPO ligand, the isoquinoline carboxamide derivative PK11195, was able to induce inhibition of cell viability in endometrial and ovarian cancer cells. In contrast, the non-site selective ligand diazepam was only slightly active or totally ineffective, suggesting that the observed effect was TSPO-specific. Furthermore, we showed that the TSPO ligand sensitizes endometrial and ovarian cancer cells to cytostatic drugs. The addition of the TSPO ligand led to a synergistic anti-neoplastic action (a dramatic enhancement of apoptosis) with either cisplatin or paclitaxel. This synergistic mechanism may be due to the fact that PK11195 blocks P-glycoprotein-mediated drug efflux at least as potently as cyclosporin A (CSA), a broad-spectrum efflux inhibitor (27). PK11195 is also frequently more effective than the MRP-selective modulator, MK-571, or the BCRP modulators, GF120918 and Ko143 (28-30). To our knowledge, PK11195 is the first MDR modulator shown to both broadly modulate ABC transporter-related and inhibit mitochondrial pore-related chemoresistance mechanisms. Therefore, PK11195 still offers advantages as a chemoresistance modulator in its ability to both broadly block drug efflux and promote apoptosis. Our findings argue for combination therapies of platinum or taxans with TSPO ligands, and suggest that it is possible to lower the doses of chemotherapeutic drugs used in the treatment of both cancers and thus reduce cytotoxicity to normal cells.

The TSPO-specific ligand PK11195 exhibited antiproliferative effects in endometrial and ovarian cancer cells at micromolar concentrations, while sparing nonmalignant endometrial epithelial cells. At nanomolar concentrations, TSPO-specific ligands had no effect on cell growth, confirming the findings of Bruce et al (31). The role of TSPO in PK11195induced apoptosis is controversial. PK11195 binds to TSPO in vivo at nanomolar concentrations (7) and the mitotic effects of nanomolar concentrations of TSPO-specific ligands have been described (32), although PK11195 induces apoptosis at much higher concentrations (50-100 $\mu \mathrm{M})$. Furthermore, siRNA experiments demonstrate that TSPO is not necessary to inhibit cell proliferation or sensitize cells to apoptosis (9).

Our data revealed that PK11195 did not activate caspase-8, indicating that PK11195-induced apoptosis was not mediated by the death receptor-driven apoptotic pathway. TSPO is an $18-\mathrm{kDa}$ protein which is located in the outer mitochondrial membrane and is associated with PTPC. The PTPC is believed to be a key regulator of stress-associated signals. Exposure to apoptosis-inducing agents may result in opening of the pore, the collapse of mitochondrial membrane potential, disruption of the outer mitochondrial membrane, and release of apoptogenic factors. These events subsequently lead to the cleavage of specific caspases, including procaspase-9, and ultimately to the cleavage of procaspase- 3 and its substrates. Mitochondrial apoptosis is known to be regulated by members of the Bcl-2 protein family such as Bcl-2 or Bax. However, the exact mechanisms regulating PTPC opening and release of apoptogenic factors are not completely understood and may vary in different cell lineages and types of stress. TSPO ligands were suggested to induce apoptosis by modulating the opening of PTPC due to TSPO's close association with proteins of the PTPC (33).

In conclusion, the results presented here suggest that PK11195 alone or in combination with chemotherapeutic drugs might be a new therapeutic option for the treatment of endometrial and ovarian cancers.

\section{Acknowledgements}

This study was supported by a grant (project code FK344 to N.T.) from the Japan Society of Gynecologic Oncology; a Grant-in-Aid (no. 21592139 to N.T.) for Scientific Research from the Ministry of Education, Culture, Sports, Science, and Technology, Japan; and a Research Fund at the Discretion of the President, Oita University.

\section{References}

1. Reinhardt MJ: Gynecologic tumors. Recent Results Cancer Res 170: 141-150, 2008.

2. Obel JC, Friberg G and Fleming GF: Chemotherapy in endometrial cancer. Clin Adv Hematol Oncol 4: 459-468, 2006.

3. Winter WE III, Maxwell GL, Tian C, et al: Tumor residual after surgical cytoreduction in prediction of clinical outcome in stage IV epithelial ovarian cancer: a Gynecologic Oncology Group Study. J Clin Oncol 26: 83-89, 2008. 
4. Decaudin D, Castedo M, Nemati F, et al: Peripheral benzodiazepine receptor ligands reverse apoptosis resistance of cancer cells in vitro and in vivo. Cancer Res 62: 1388-1393, 2002.

5. Maaser K, Höpfner M, Jansen A, et al: Specific ligands of the peripheral benzodiazepine receptor induce apoptosis and cell cycle arrest in human colorectal cancer cells. Br J Cancer 85 1771-1780, 2001.

6. Sutter AP, Maaser K, Höpfner M, et al: Specific ligands of the peripheral benzodiazepine receptor induce apoptosis and cell cycle arrest in human esophageal cancer cells. Int J Cancer 102: 318-327, 2002

7. Le Fur G, Perrier ML, Vaucher N, et al: Peripheral benzodiazepine binding sites: effect of PK 11195, 1-(2-chlorophenyl)$\mathrm{N}$-methyl-N-(1-methylpropyl)-3-isoquinolinecarboxamide. I. In vitro studies. Life Sci 32: 1839-1847, 1983.

8. Papadopoulos V, Baraldi M, Guilarte TR, et al: Translocator protein $(18 \mathrm{kDa})$ : new nomenclature for the peripheral-type benzodiazepine receptor based on its structure and molecular function. Trends Pharmacol Sci 27: 402-409, 2006.

9. Gonzalez-Polo RA, Carvalho G, Braun T, et al: PK11195 potently sensitizes to apoptosis induction independently from the peripheral benzodiazepine receptor. Oncogene 24: 7503-7513, 2005.

10. Susin SA, Zamzami N, Castedo M, et al: The central executioner of apoptosis: multiple connections between protease activation and mitochondria in Fas/APO-1/CD95- and ceramide-induced apoptosis. J Exp Med 186: 25-37, 1997.

11. Zoratti $\mathrm{M}$ and Szabò I: The mitochondrial permeability transition. Biochim Biophys Acta 1241: 139-176, 1995.

12. Ly JD, Grubb DR and Lawen A: The mitochondrial membrane potential (deltapsi(m)) in apoptosis; an update. Apoptosis 8: $115-128,2003$

13. De Jong D, Prins FA, Mason DY, Reed JC, van Ommen GB and Kluin PM: Subcellular localization of the bcl-2 protein in malignant and normal lymphoid cells. Cancer Res 54: 256-260, 1994.

14. Kroemer G: The proto-oncogene Bcl-2 and its role in regulating apoptosis. Nat Med 3: 614-620, 1997.

15. Muscarella DE, O'Brien KA, Lemley AT and Bloom SE: Reversal of Bcl-2-mediated resistance of the EW36 human B-cell lymphoma cell line to arsenite- and pesticide-induced apoptosis by PK11195, a ligand of the mitochondrial benzodiazepine receptor. Toxicol Sci 74: 66-73, 2003.

16. Hirsch T, Marzo I and Kroemer G: Role of the mitochondrial permeability transition pore in apoptosis. Biosci Rep 17: 67-76, 1997.

17. Ferry A, Jaillon P, Lecocq B, Lecocq V and Jozefczak C: Pharmacokinetics and effects on exercise heart rate of PK 11195 (52028 RP), an antagonist of peripheral benzodiazepine receptors, in healthy volunteers. Fundam Clin Pharmacol 3: 383-392, 1989

18. Ansseau M, von Frenckell R, Cerfontaine JL and Papart P: Pilot study of PK 11195 , a selective ligand for the peripheral-type benzodiazepine binding sites, in inpatients with anxious or depressive symptomatology. Pharmacopsychiatry 24: 8-12, 1991.
19. Batra S and Iosif CS: Elevated concentrations of mitochondria peripheral benzodiazepine receptors in ovarian tumors. Int J Oncol 12: 1295-1298, 1998.

20. Batra S and Iosif CS: Peripheral benzodiazepine receptor in human endometrium and endometrial carcinoma. Anticancer Res 20: 463-466, 2000

21. Kalogiannidis I, Bobos M, Papanikolaou A, et al: Immunohistochemical bcl-2 expression, 553 overexpression, PR and ER status in endometrial carcinoma and survival outcomes. Eur J Gynaecol Oncol 29: 19-25, 2008.

22. Sagarra RA, Andrade LA, Martinez EZ, Pinto GA, Syrjänen KJ and Derchain SF: P53 and Bcl-2 as prognostic predictors in epithelial ovarian cancer. Int J Gynecol Cancer 12: 720-727, 2002.

23. Takai N, Ueda T, Nasu K and Narahara H. Erucylphosphocholine shows a strong anti-growth activity in human endometrial and ovarian cancer cells. Gynecol Oncol 111: 336-343, 2008.

24. Hirsch T, Marchetti P, Susin SA, et al: The apoptosis-necrosis paradox. Apoptogenic proteases activated after mitochondrial permeability transition determine the mode of cell death. Oncogene 15: 1573-1581, 1997.

25. Okaro AC, Fennell DA, Corbo M, Davidson BR and Cotter FE: Pk11195, a mitochondrial benzodiazepine receptor antagonist, reduces apoptosis threshold in $\mathrm{Bcl}-\mathrm{X}(\mathrm{L})$ and $\mathrm{Mcl}-1$ expressing human cholangiocarcinoma cells. Gut 51: 556-561, 2002.

26. Zamzami N, Susin SA, Marchetti P, et al: Mitochondrial control of nuclear apoptosis. J Exp Med 183: 1533-1544, 1996.

27. Qadir M, O'Loughlin KL, Fricke SM, et al: Cyclosporin A is a broad-spectrum multidrug resistance modulator. Clin Cancer Res 11: 2320-2326, 2005.

28. Gekeler V, Ise W, Sanders KH, Ulrich WR and Beck J: The leukotriene LTD4 receptor antagonist MK571 specifically modulates MRP-associated multidrug resistance. Biochem Biophys Res Commun 208: 345-352, 1995.

29. De Bruin M, Miyake K, Litman T, Robey R and Bates SE: Reversal of resistance by GF120918 in cell lines expressing the ABC half-transporter, MXR. Cancer Lett 146: 117-126, 1999.

30. Allen JD, van Loevezijn A, Lakhai JM, et al: Potent and specific inhibition of the breast cancer resistance protein multidrug transporter in vitro and in mouse intestine by a novel analogue of fumitremorgin C. Mol Cancer Ther 1: 417-425, 2002.

31. Bruce JH, Ramirez AM, Lin L, Oracion A, Agarwal RP and Norenberg MD: Peripheral-type benzodiazepines inhibit proliferation of astrocytes in culture. Brain Res 564: 167-170, 1991.

32. Beinlich A, Strohmeier R, Kaufmann M and Kuhl H: Specific binding of benzodiazepines to human breast cancer cell lines. Life Sci 65: 2099-2108, 1999.

33. Campanella M, Szabadkai G and Rizzuto R: Modulation of intracellular $\mathrm{Ca}^{2+}$ signalling in HeLa cells by the apoptotic cell death enhancer PK11195. Biochem Pharmacol 76: 1628-1636, 2008. 